$\mathrm{Nucl}$ eot $\mathrm{i}$ de compositi on of the genom $\mathrm{c}$ and prot ei $n$-codi ng sequences i $n$ the two DNA st $r$ ands

\begin{tabular}{|l|l|}
\hline 著者 & Nakashi ma H r oshi \\
\hline $\begin{array}{l}\text { j our nal or } \\
\text { publ i cat i on t i t l e }\end{array}$ & I FMBE Proceedi ngs \\
\hline vol une & 21 I FMBE \\
\hline number & 1 \\
\hline page $r$ ange & $867-870$ \\
\hline year & 2008 01- 01 \\
\hline URL & ht t p: //hdl . handl e. net /2297/25765 \\
\hline
\end{tabular}




\title{
Nucleotide Composition of the Genomic and Protein-Coding Sequences in the two DNA Strands
}

\author{
Hiroshi Nakashima \\ Division of Health Science, Kanazawa University, Kanazawa, Japan
}

\begin{abstract}
The nucleotide composition of protein-coding genes in the two DNA strands of Escherichia coli, Bacillus subtilis, Methanococcus jannaschii and mitochondrial genes of human and fruit fly was studied. E. coli, B. subtilis and $M$. jannaschii indicated compositional asymmetry in their genomic sequences. The protein-coding genes of $E$. coli and $B$. subtilis showed the influence of compositional asymmetry in their compositions, however, no influence was observed in $M$. jannaschii. Mitochondrial protein-coding genes showed significant difference in composition in the two DNA strands. The deviation of nucleotide composition in the two DNA strands is discussed.
\end{abstract}

Keywords - nucleotide composition, compositional asymmetry, leading and lagging strands, cumulative GC skew

\section{INTRODUCTION}

Comparison of nucleotide composition is a simple way to analyze the character of nucleotide sequences. In a double stranded DNA, adenine pairs with thymine and guanine pairs with cytosine, therefore, the amount of adenine is equal to thymine and guanine is equal to cytosine in DNA. This is known as Chargaff's first rule. This rule also roughly holds for single stranded DNA in some species. This is known as Chargaff's second rule. It is reported that guanine plus cytosine $(\mathrm{G}+\mathrm{C})$ content is fairly constant in a bacterial genome. However, $\mathrm{G}+\mathrm{C}$ content differs considerably among species, and ranges from $25 \%$ to $75 \%$ [1]. Karlin's group has reported that genes from bacteria have their species specific nucleotide compositions based on the relative ratio between observed and expected dinucleotide frequencies [24]. Even genes encoding homologous proteins from different species were discriminated by their dinucleotide frequencies [5]. The protein-coding genes from nine genomes were classified into their species with accuracy of $80 \%$ in terms of dinucleotide frequencies [6].

The compositional asymmetry in a genomic sequence has been reported [7-10]. It is considered that the biased mutational occurrences due to the different replication mechanism between leading and lagging strands might be the cause of compositional asymmetry. Plots of cumulative GC skew of E. coli genomic sequence indicated maximum and minimum points [9]. The minimum point is consistent with the site of replication origin and the maximum with terminus, and the nucleotide composition asymmetry reversed at these two points in the genomic sequence. It is known that the leading strand contains more guanine than cytosine compared to lagging strand. The deviation between adenine and thymine is smaller than that between guanine and cytosine. Due to the compositional asymmetry in a genomic sequence, it is anticipated that the nucleotide composition of protein-coding genes would be different between the genes in leading and lagging strands. The deviation of nucleotide composition of protein-coding genes in the two DNA strands was investigated in this study. It is reported that the nucleotide composition of genes in the light (L) and heavy $(\mathrm{H})$ strands of mitochondrial DNA (mtDNA) is different [11]. Mammalian mtDNA encodes thirteen proteins, which are components of enzyme complexes of the inner mitochondrial membrane that function in electron transport chain and hence oxidative phosphorylation. The proteins encoded on mtDNA are rich in hydrophobic amino acids [12]. mtDNAs of human, Homo sapiens [13] and fruit fly, Drosophila melanogaster [14] were also studied.

\section{MATERIALS AND METHODS}

The genome sequences of E. coli [15], B. subtilis [16], and $M$. jannaschii [17] were obtained from the National Center for Biotechnology Information (NCBI) (ftp://ftp. ncbi.nih.gov/genomes/), and mitochondrial genomes of human and fruit fly were retrieved from the site of eukaryote organelles of NCBI. The protein-coding nucleotide sequences, which are included in the NCBI ffn file, were used to calculate nucleotide compositions. The nucleotide composition of genomic sequence was calculated using genomic sequence, NCBI gbk file. The protein-coding nucleotide sequences of mtDNAs were obtained according to the annotation of the genomes and their compositions were calculated. The TA and GC skews of genomic sequence were calculated as

$$
\begin{aligned}
& \text { TA skew }=(T-A) /(T+A) \\
& \text { GC skew }=(G-C) /(G+C)
\end{aligned}
$$

using 1-kbp non-overlapping windows.

The clockwise genomic sequence from the origin to terminus and that from the terminus to origin were obtained. The nucleotide composition of the two genomic sequences 
was calculated. The strand which had more guanine than cytosine was regarded as leading strand.

The protein-coding genes in a clockwise strand from the origin to terminus and those in the counterclockwise strand from the terminus to origin were combined together and their average nucleotide composition and that at the third codon position were calculated. Similarly, the proteincoding genes in a counterclockwise strand from the origin to terminus and those in the clockwise strand from the terminus to origin were combined together and their average compositions were calculated. The genes of less than 150 base pairs were excluded in the calculation. The nucleotide composition of whole mtDNA of human and fruit fly was calculated, separately.

\section{RESULtS}

\section{A. Cumulative GC skew}

The cumulative AT/GC skew profiles were obtained by cumulative addition of the skew values along the sequences. The GC skew profile of $E$. coli genomic sequence is shown in Fig.1. The maximum and minimum sites are located at $1.58 \mathrm{Mbp}$ and $3.92 \mathrm{Mbp}$, they correspond to the terminus and origin of DNA replication [9]. Similarly, GC skew profiles of $B$. subtilis and $M$. jannaschii were obtained using their genomic sequences. The profiles also indicated the maximum and minimum points. However, the AT/GC skew profiles of mtDNAs of human and fruit fly gave no maximum nor minimum.

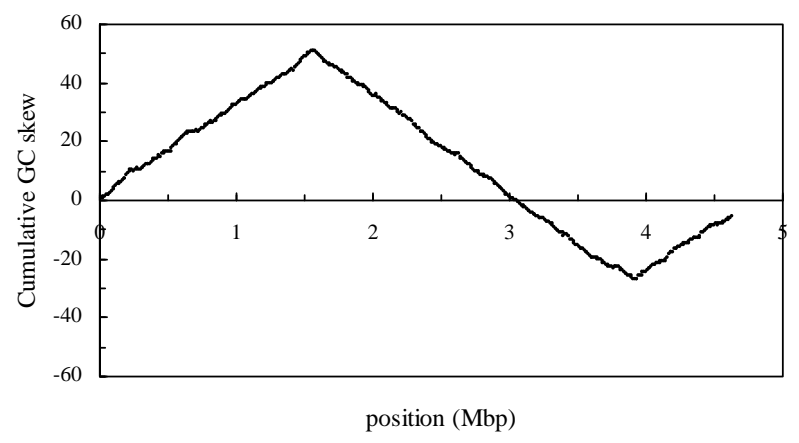

Fig. 1. Cumulative GC skew of E. coli genomic sequence.

In E. coli and B. subtilis, the minimum and maximum points were in correspondence with the experimentally determined origin and terminus of DNA replication [9]. In $M$. jannaschii, the sites of origin and terminus are not experimentally determined. Assuming the minimum and maxi- mum points are the sites of origin and terminus, the nucleotide composition was calculated.

\section{B. Nucleotide composition of genomic sequences}

The nucleotide composition of genomic sequences is listed in Table 1. In E. coli, guanine was $1.6 \%$ greater than cytosine in clockwise genomic sequence from the origin to terminus. Conversely, cytosine was $1.6 \%$ greater than guanine in clockwise genomic sequence from the terminus to origin. It is known that DNA replication proceeds bidirectionally from origin to terminus in E. coli, and leading strand has more guanine than cytosine. So, the clockwise sequence from origin to terminus and counterclockwise sequence from terminus to origin must be leading sequence. Conversely, cytosine was greater than guanine in lagging strand.

Similarly, the genomic sequence which has more guanine than cytosine was regarded as leading sequence both in B. subtilis and M. jannaschii. Consequently, the genomic sequence which has more cytosine than guanine was lagging sequence. The deviation between guanine and cytosine was greater than that between adenine and thymine in three species. This result reconfirmed that the asymmetry of GC is greater than that of AT [9]. The deviation between guanine and cytosine and that between adenine and thymine in leading strand was close to the corresponding one in lagging strand with opposite sign.

The largest deviation of nucleotide composition between leading and lagging genomic sequences was $1.8 \%$ of guanine in E. coli, $3.9 \%$ of guanine in B. subtilis, and $1.6 \%$ of cytosine in $M$. jannaschii.

The nucleotide composition of human mtDNA was significantly deviated from the Chargaff's second rule. Guanine was deficient compared to cytosine and thymine was lesser compared to adenine. The fruit fly mtDNA has high $\mathrm{A}+\mathrm{T}$ content of $82.2 \%$.

\section{Nucleotide composition of protein-coding sequences}

The nucleotide composition of protein-coding sequences in the leading and lagging strands is listed in Table 1 . In E. coli, guanine $>$ cytosine and adenine $\approx$ thymine were observed both in the leading and lagging strands for the protein-coding whole sequence. At the third codon position, guanine $>$ cytosine and thymine $>$ adenine in the leading strand, and cytosine $>$ guanine and thymine $>$ adenine in the lagging strand was observed. The richness of cytosine in the lagging strand is consistent with that in the genomic sequence. Thymine was preferred to adenine at the third codon position both in leading and lagging strands in E. coli. 
In $B$. subtilis, the trend of guanine $>$ cytosine and adenine $>$ thymine was observed both in the leading and lagging strands for the protein-coding whole sequence. At the third codon position, guanine $>$ cytosine and thymine $>$ adenine was observed in the leading strand, and cytosine $>$ guanine and thymine $>$ adenine in the lagging strand. The richness of cytosine in the lagging strand was consistent with that in the genomic sequence. Thymine was preferred to adenine at the third codon position both in leading and lagging strands in B. subtilis as observed in E. coli.

Table 1. Nucleotide composition of genomic and protein-coding sequences.

\begin{tabular}{|c|c|c|c|c|c|}
\hline \multirow[t]{2}{*}{ species } & \multirow[t]{2}{*}{ feature } & \multicolumn{4}{|c|}{ composition (\%) } \\
\hline & & A & $\mathrm{T}$ & G & $\mathrm{C}$ \\
\hline \multirow[t]{7}{*}{ E. coli } & genomic sequence & & & & \\
\hline & $\begin{array}{l}\text { from origin to terminus } \\
\text { clockwise, leading strand } \\
\text { from terminus to origin }\end{array}$ & 24.4 & 24.6 & 26.3 & 24.7 \\
\hline & $\begin{array}{l}\text { clockwise, lagging strand } \\
\text { protein-coding sequences }\end{array}$ & 24.8 & 24.6 & 24.5 & 26.1 \\
\hline & $\begin{array}{l}2313 \text { genes in leading strand } \\
\text { whole sequence }\end{array}$ & 24.3 & 24.3 & 27.7 & 23.7 \\
\hline & codon third position & 18.4 & 26.8 & 29.8 & 25.0 \\
\hline & $\begin{array}{l}1915 \text { genes in lagging strand } \\
\text { whole sequence }\end{array}$ & 24.7 & 24.2 & 26.3 & 24.8 \\
\hline & codon third position & 19.0 & 26.1 & 27.3 & 27.6 \\
\hline \multirow[t]{7}{*}{ B. subtilis } & genomic sequence & & & & \\
\hline & $\begin{array}{l}\text { from origin to terminus } \\
\text { clockwise, leading strand } \\
\text { from terminus to origin }\end{array}$ & 29.3 & 26.7 & 23.8 & 20.2 \\
\hline & $\begin{array}{l}\text { clockwise, lagging strand } \\
\text { protein-coding sequences }\end{array}$ & 27.2 & 29.7 & 19.9 & 23.2 \\
\hline & $\begin{array}{l}3004 \text { genes in leading strand } \\
\text { whole sequence }\end{array}$ & 30.5 & 25.9 & 24.3 & 19.3 \\
\hline & codon third position & 27.4 & 29.0 & 24.0 & 19.6 \\
\hline & $\begin{array}{l}1040 \text { genes in lagging strand } \\
\text { whole sequence }\end{array}$ & 30.3 & 26.4 & 22.3 & 21.0 \\
\hline & codon third position & 27.5 & 28.4 & 21.0 & 23.1 \\
\hline \multirow[t]{7}{*}{ M. jannaschii } & genomic sequence & & & & \\
\hline & $\begin{array}{l}\text { from origin to terminus } \\
\text { clockwise, leading strand } \\
\text { from terminus to origin }\end{array}$ & 35.0 & 33.9 & 16.2 & 14.9 \\
\hline & $\begin{array}{l}\text { clockwise, lagging strand } \\
\text { protein-coding sequences }\end{array}$ & 33.7 & 34.3 & 15.5 & 16.5 \\
\hline & $\begin{array}{l}950 \text { genes in leading strand } \\
\text { whole sequence }\end{array}$ & 38.2 & 29.9 & 20.8 & 11.1 \\
\hline & codon third position & 39.9 & 35.2 & 15.8 & 9.1 \\
\hline & $\begin{array}{l}751 \text { genes in lagging strand } \\
\text { whole sequence }\end{array}$ & 38.4 & 29.8 & 20.6 & 11.2 \\
\hline & codon third position & 40.3 & 35.0 & 15.3 & 9.4 \\
\hline \multirow[t]{7}{*}{ H. sapiens } & mtDNA & & & & \\
\hline & $\begin{array}{l}\text { genomic sequence of L strand } \\
12 \text { genes in L strand }\end{array}$ & 30.9 & 24.6 & 13.2 & 31.3 \\
\hline & whole sequence & 29.7 & 25.7 & 11.7 & 32.9 \\
\hline & codon third position & 37.3 & 15.5 & 5.6 & 41.6 \\
\hline & 1 gene in $\mathrm{H}$ strand & & & & \\
\hline & whole sequence & 19.4 & 37.5 & 35.8 & 7.3 \\
\hline & codon third position & 19.4 & 41.2 & 36.0 & 3.4 \\
\hline \multirow[t]{7}{*}{ D. melanogaster } & mtDNA & & & & \\
\hline & genomic sequence of L strand & 41.8 & 40.4 & 7.6 & 10.2 \\
\hline & whole sequence & 34.1 & 43.4 & 10.0 & 12.5 \\
\hline & codon third position & 46.8 & 47.7 & 1.1 & 4.4 \\
\hline & 4 genes in $\mathrm{H}$ strand & & & & \\
\hline & whole sequence & 30.7 & 49.0 & 12.7 & 7.6 \\
\hline & codon third position & 42.4 & 52.0 & 4.8 & 0.8 \\
\hline
\end{tabular}
strands was $1.4 \%$ of guanine in E. coli, $2.0 \%$ of guanine in B. subtilis, and $0.2 \%$ of guanine/adenine in M. jannaschii. Similarly, the largest deviation at the third codon position was $2.6 \%$ of cytosine in E. coli, $3.5 \%$ of cytosine in B. subtilis, and $0.5 \%$ of guanine in $M$. jannaschii. The deviation was larger at the third codon position than the whole sequence.

The leading strand has more protein-coding genes than the lagging strand in three species, the leading strand in $B$. subtilis has 3004 genes about three times more genes than the lagging strand of 1040 genes.

The fruit fly mtDNA has high $\mathrm{A}+\mathrm{T}$ content and the guanine is $7.6 \%$. The deficiency of guanine/cytosine at the third codon position of protein-coding sequence was significant. Guanine content was $1.1 \%$ on the $\mathrm{L}$ strand and cytosine was $0.8 \%$ on the $\mathrm{H}$ strand.

\section{Discussion}

The average nucleotide compositions of protein-coding genes in the leading and lagging strands were simply compared to detect compositional differences. The distribution of nucleotide composition of A, T, G and C in proteincoding genes indicated normal distribution with a single peak both in the leading and lagging strands in three species.

The average nucleotide composition of protein-coding genes in a clockwise strand from the origin to terminus and that in the counterclockwise strand from the terminus to origin were almost identical in three species. This holds for the genes in the alternative strands.

The G-C and T-A deviations were different for leading and lagging coding sequences, and the difference was greater at the third codon position in E. coli and B. subtilis. This result indicated that the compositional deviation is increased when the constraint on amino acids is smaller. To exclude the constraint of amino acids, the composition at the third codon position of eight kinds of four-fold degenerate codons (Ala: GCN, Arg: CGN, Gly: GGN, Leu: CUN, Pro: CCN, Ser: UCN, Thr: ACN and Val: GUN) in leading and 
lagging sequences was investigated. The genes which have less than 50 four-fold degenerate codons were excluded to calculate average composition. The average composition is listed in Table 2.

Table 2. Average composition at the third position of eight four-fold codons.

\begin{tabular}{llcrrr}
\hline species & feature & \multicolumn{3}{c}{ composition (\%) } \\
& & A & T & \multicolumn{1}{c}{ G } & C \\
\hline E. coli & 2079 genes in leading strand & 14.0 & 23.9 & 35.8 & 26.3 \\
& 1718 genes in lagging strand & 14.9 & 22.4 & 32.7 & 30.0 \\
B. subtilis & 2515 genes in leading strand & 25.2 & 26.4 & 27.6 & 20.8 \\
& 843 genes in lagging strand & 25.8 & 25.8 & 23.2 & 25.2 \\
M. jannaschii & 685 genes in leading strand & 43.7 & 39.8 & 8.1 & 8.4 \\
& 525 genes in lagging strand & 43.9 & 39.9 & 7.7 & 8.5 \\
H. sapiens & mtDNA & & & & \\
& 11 genes in L strand & 39.3 & 12.9 & 5.4 & 42.4 \\
& 1 gene in H strand & 21.6 & 35.2 & 39.8 & 3.4 \\
D. melanogaster & mtDNA & & & & \\
& 7 genes in L strand & 50.0 & 44.2 & 2.3 & 3.5 \\
& 3 genes in H strand & 28.4 & 64.7 & 6.2 & 0.7 \\
\hline
\end{tabular}

The richness of guanine over cytosine in leading strand was clear in $E$. coli and $B$. subtilis. The largest deviation of nucleotide composition at the third position of eight fourfold codons of protein coding sequences between leading and lagging strands was $3.7 \%$ of cytosine in E. coli, $4.4 \%$ of guanine/cytosine in B. subtilis, and $0.4 \%$ of guanine in $M$. jannaschii. This deviation was larger than that at the third codon position (Table 1) in E. coli and B. subtilis. However, the deviation in genomic sequence was largest in $M$. jannaschii. M. jannaschii belongs to thermophilic archaea with optimum growth temperature of $85^{\circ} \mathrm{C}$ [18]. To get thermal stability for their DNA and proteins, the nucleotide composition may have no room to obey compositional asymmetry. The protein-coding sequences occupy $87 \%$ of genomic sequence of $M$. jannaschii [19], therefore, the remaining $13 \%$ of non-coding sequence must be the cause of the observed compositional asymmetry.

Mammalian mtDNAs have two origins of DNA replication for the $\mathrm{H}$ and $\mathrm{L}$ strands. The replication of mtDNA starts at $\mathrm{L}$ strand and $\mathrm{H}$ strand remained for hours as singlestranded. Deamination occurs much more frequently on single-stranded than on double-stranded DNA, and this yields many mutations in mtDNA [20]. Therefore, the nucleotide composition of mtDNA genes in the two DNA strands showed a large deviation.

\section{REFERENCES}

1. Muto A, Osawa S (1987) The guanine and cytosine content of geomic DNA and bacterial evolution. Proc Natl Acad Sci USA 84: 166-169

2. Karlin S, Cardon LR (1994) Computational DNA sequence analysis. Annu Rev Microbiol 48: 619-654

3. Karlin S, Burge C (1995) Dinucleotide relative abundance extremes: a genomic signature. Trends Genet 11: 283-290
4. Karlin S, Mrázek J, Campbell AM (1997) Compositional biases of bacterial genomes and evolutionary implications. J Bacteriol 179: 3899-3913

5. Nakashima H, Nishikawa K, Ooi T (1997) Differences in dinucleotide frequencies of human, yeast, and Escherichia coli genes. DNA Res 4: 185-192

6. Nakashima H, Ota M, Nishikawa K et al. (1998) Genes from nine genomes are separated into their organisms in the dinucleotide composition space. DNA Res 5: 251- 259

7. Lobry JR (1996) Asymmetric substitution patterns in the two DNA strands of bacteria. Mol Biol Evol 13: 660-665

8. Mrázek J, Karlin S (1998) Strand compositional asymmetry in bacterial and large viral genomes. Proc Natl Acad Sci USA 95: 37203725

9. Grigoriev A (1998) Analyzing genomes with cumulative skew diagrams. Nucleic Acids Res 26: 2286-2290

10. Touchon M, Nicolay S, Audit B et al. (2005) Replication-associated strand asymmetries in mammalian genomes: toward detection of replication origins. Proc Natl Acad Sci USA 102: 9836-9841

11. Martin AP (1995) Metabolic rate and directional nucleotide substitution in animal mitochondrial DNA. Mol Biol Evol 12: 1124-1131

12. Nakashima H, Nishikawa K, Ooi T (1990) Distinct character in hdrophobicity of amino acid compositions of mitochondrial proteins. Proteins 8: 173-178

13. Anderson S, Bankier AT, Barrell GB et al. (1981) Sequence and organization of the human mitochondrial genome. Nature 290: 457465

14. Garesse R (1988) Drosophila melanogaster mitochondrial DNA: gene organization and evolutionary considerations. Genetics 118: 649-663

15. Blattner FR, Plunkett GIII, Bloch CA et al. (1997) The complete genome sequence of Escherichia coli K-12. Science 277: 1453-1462

16. Kunst F, Ogasawara N, Moszer I et al. (1997) The complete genome sequence of the gram-positive bacterium Bacillus subtilis. Nature 390: 249-256

17. Bult CJ, White O, Olsen GJ et al. (1996) Complete genome sequence of the methanogenic archaeon, Methanococcus jannaschii. Science 273: 1058-1073

18. Nakashima H, Fukuchi S, Nishikawa K (2003) Compositional changes in RNA, DNA and proteins for bacterial adaptation to higher and lower temperatures. J Biochem 133: 507-513

19. Nakashima H, Nishikawa K (2000) The genomic DNA sequences of various species are distinctively distributed in nucleotide composition space. Res Commun Biochem Cell Mol Biol 4: 25-45

20. Xia X (2005) Mutation and selection on the anticodon of tRNA genes in vertebrate mitochondrial genomes. Gene 345: 13-20

The address of the corresponding author:

Author: Hiroshi Nakashima

Institute: Department of Clinical Laboratory Science, Graduate Course of Medical Science and Technology, Division of Health Science, Kanazawa University

Street: Kodatsuno 5-11-80

City: Kanazawa 920-0942

Country: Japan

Email: naka@kenroku.kanazawa-u.ac.jp 